Mathematics for Technical Students

By Frederick G. W. Brown. Part 1 (First Year Course). Pp. $\mathrm{x}+215+\mathrm{xviii}$. 3s. Part 2 (Second Year Course). Pp. $\mathrm{x}+217-491+\mathrm{xxv}$. 3s. 6d. (London : Macmillan and Co., Ltd., 1936.)

IT is to be hoped that all teachers of mathematics in technical schools and evening institutes will have the opportunity of seeing these two books; for they provide a preliminary two-year course in mathematies which is exactly what is wanted at the present time.

After a revision of the simple operations of arithmetic, the student is introduced to the notation of algebra and made to see the value of this new weapon, until, finally, he should be able to solve arithmetical problems by means of a simple equation. This is followed by a short informal course of theoretical geometry; time spent on this section will be amply rewarded in the later stages of the course.

The concluding chapters of Part 1 deal with applications of previous work to the area of simple rectilinear figures and circles and to the volume of bodies of uniform cross-section. Some teachers will no doubt prefer to take this work earlier in the course - and there is much to be said for this view ; teachers will find no difficulty in doing this.

Part 2 is necessarily more formal in character than Part 1. The first three chapters deal with logarithms and their many applications, plenty of useful exercises being provided; simple equations in two unknowns, fractions, harder fractions and quadratic equations complete the work in algebra. The remaining chapters deal with numerical trigonometry, harder mensuration and graphs, and applications of Simpson's rule. This last chapter could serve as a link in an introduction to the calculus for those students who proceed further with mathematics.

Typical sets of examination papers and useful mathematical tables are provided at the end of the book.

Teachers in evening schools have many problems to meet : the minimum number of students to form a class, intermittent attendance, the weariness of students who have done a day's work and the difficulty of an adequate supply of text-books; but if evening school students could handle and use these two volumes, examiners would soon find a considerable improvement in elementary mathematics.

L. C.

\section{A Text-Book of Physical Chemistry}

By Sylvanus J. Smith. Pp. xii +355 . (London : Macmillan and Co., Ltd., 1936.) 5s. $6 d$.

THrs book is intended primarily to provide a course of physical chemistry for students preparing for the Higher School Certificate Examinations in science, also for candidates for university open scholarships, and for the First Examination for medical degrees. Such students will find the book very useful. In its 345 pages of text, the author more than covers the field of physical chemistry required by these exam. inations.
The subject matter is generally brought right up to date, but the older theories are also given their fair place. The section on the structure of the atomic nucleus, however, should now include a mention of the modern theory of its constitution from protons and neutrons. The excellent chapters on catalysis and colloids touch on many important industrial applications. A good selection of examination questions is given at the end of each chapter, with answers to the numerical examples in the appendix. The text is illustrated throughout with clear and helpful diagrams. Fig. 87 cannot correctly be described as the "Bunsen-Roscoe Actinometer" since it shows a mercury meniscus used in contact with chlorine gas.

The treatment is neither too elementary nor too advanced, and seems to be just the right standard required by the examinations for which the book is written.

\section{Graphical Solutions}

By Prof. Charles O. Mackey. Pp. vii +130 . (New York: John Wiley and Sons, Inc.; London : Chapman and Hall, Ltd., 1936.) 12s. 6d. net.

GRAPHICAL and mechanical representations of practical equations are especially useful to the engineer, and this volume has been written to provide a systematic course in the subject. The first four chapters are devoted to stationary adjacent and sliding scales; network or intersection and alignment charts for equations in three variables and combinations of all these methods of solution. In the final chapter, the fitting of equations to experimental data is discussed. The treatment is quite elementary and involves only a working knowledge of logarithms, algebra and plane geometry, while a little calculus is required in the section on empirical equations. With the volume is provided a very clear reproduction of the logarithmic scales prepared by the late Prof. Lipka.

To those who have to deal with practical graphical computation, this book should prove very useful, instructive and interesting.

Sammlung chemischer und chemischtechnischer Vorträge

Begründet von F. B. Ahrens. Herausgegeben von Prof. Dr. R. Pummerer-Erlangen. Neue Folge Heft 33: Die Azoxyverbindungen: eine Monographie. Von Dr. Eugen Müller. Pp. 40. (Stuttgart: Ferdinand Enke, 1936.) 3.40 gold marks.

The mode of representing the structure of the important class of the azoxy-compounds has recently undergone a change, based originally on chemical evidence provided by Angeli, and confirmed by the isolation of optically active substances by Marvel and E. Müller. The new formulation is a consequence also of the physical properties of the substances. The present monograph sets out clearly and accurately the grounds for the present representation of the structure of the azoxy-compounds, with full references to the literature. It is a useful contribution to the literature on the organic chemistry of nitrogen. 